\title{
"How Can I Help You?": Perspectives from a Patient with a Hearing Loss
}

Rachel Kolb

\section{The Experience}

"So, how are you feeling today?" I retrieve the question off the doctor's lips and compose myself before launching into an explanation. She is a stranger to me, and though she can easily see on my medical records that I am deaf, I wonder if she knows what that entails for our conversation. I wonder if she knows that, for me, deafness is not just a medical condition, a malady to be treated with prescriptions and therapeutic remedies. It is a dominant force that shapes the way I communicate, the way I understand my world. It has influenced my life experiences as much as any physical characteristic can, even while in another sense it is no different than, say, wearing contact lenses. I see through the lens of my deafness, and I use a particular set of strategies to surmount any barriers it sets before me, even while it is a deep and inescapable part of who I am.

I also wonder if my doctor knows that, despite the "profound hearing loss" designation that must dominate my medical file, I come in today just as anyone else would, wanting to have a direct conversation about my body and my condition. I am sure she does, since she is treating me as she would any other patient. She listens, speaks normally, and looks down at her clipboard from time to time. I appreciate this; I am simply myself, and I am here for a routine physical. Yet difficulties seep in when she treats me like she would treat any other person. This is the paradoxical reality of my life: in many ways I feel and function just like anyone else, but I must often behave differently if I am to communicate on an equal plane.

My doctor continues looking down to write notes as I speak, but sometimes she throws me off balance by saying something when she is not looking at me. Sometimes, later in the examination, she moves around the room to where I cannot see her as clearly, often to retrieve a new implement, but does not think to stop talking. The part of the physical when she stands behind me with a stethoscope and asks me to breathe deeply never works too well. My strategy, in the lack of any visual cues, is to take deep breaths at random and hope they give her some useful information. In dentist's offices or other medical situations, she places a surgical mask over her face, cutting me off from communication entirely.

There is an easy solution for this: I can politely interrupt what she is doing and say, "I'm reading your lips. Could you please slow down, look at me, and speak more clearly?" In most cases, this works well. She adjusts her mannerisms and I breathe a sigh of relief as the words flow off her clear, articulate lips. Still, lipreading is less of a fix-all solution than it initially appears, for it is not quite like reading the words in a book. Years of speech therapy and immersion in the hearing world have taught me to work with the facial features of most people I meet, to contrive the appearance of functioning like a hearing person myself, but work is the key word in this statement: lipreading is incredibly hard work.

When I lipread, in the medical setting or elsewhere, I settle down and fixate on my companion's face, observing the minute ways its muscles move. Some people's features are more naturally expressive than others, and their words reach my eyes more clearly. What to do with the others? The men who have facial hair that obstructs what they are saying, the people who mumble or speak quickly or who have thin lips that hardly move at all? What about the people whose accents are foreign to me, whether they hail from Boston or somewhere farther away like Scotland or Singapore, and whose way of articulating their words clashes with my mental model of what speech looks like? When I meet people whose physiques challenge my ability to adapt, I resort to guesswork. While still attempting to pay attention to what they are saying in real time, I process what they have just said, what it could have meant according to the context and according to what I'm seeing right now. But guesswork doesn't only figure into conversations with people whose faces make them hard to lipread. It is an inherent part of lipreading itself. 
When I lipread, I enter the difficult territory of trying to use one sense to retrieve the information that was meant for another. My sight informs me of what my hearing cannot grasp, but spoken words were not meant for sight alone. I have read that only thirty percent of spoken English is clearly discernable from lipreading alone., ${ }^{1,2}$ Beyond that threshold, whatever accuracy I achieve is due to guesswork, context, determining whether that word I saw contained a " $b$ " or a " $\mathrm{p}$," $\mathrm{a}$ " $\mathrm{t}$ " or a " $\mathrm{d}$. " (Their only difference: one is voiced and one is not.) I use information I know, or preexisting clues I've been given, to try to figure out what I did not catch. But how am I supposed to guess what word I'm seeing when my doctor is using medical terminology I do not know, or when she prescribes a medication I have never heard of before and cannot even pronounce?

Unfamiliar terminology surfaces in all situations, making lipreading more difficult, but in the medical setting I feel heightened pressure to get it right. The conversations I have with my doctor are not like the small talk I might have at a café. When I visit her office, I enter an intimate conversation about my body and its condition; I yearn to grasp her insights. My failure to communicate well because I am deaf is not only potentially hazardous for my health. It also fosters a mindset in which I feel far less empowered to look after my own physical well-being. Or, to ask a broader question: if I cannot understand a doctor's insights about my body, what happens to my sense of autonomy and control over my life?

One might ask, at this point, why I do not use a sign language interpreter to help me function better in the medical setting. At one point, I did. When I was a child, my mother always came along to my doctor's appointments to be my interpreter. But even with her support, learning to communicate for myself was paramount: I longed after the independence that comes with direct communication. I still do. My speech and lipreading skills enable me to communicate well one-on-one without a professional interpreter, although I know the option is there. I prefer to take my communication into my own hands, although I realize that this is a matter of personal choice.

Some other deaf and hard-of-hearing people do not (or cannot) make this choice - and, in any case, when I or anyone else speaks of "hearing loss," we speak of a dizzying spectrum of experiences and abilities, from the deaf to the hard-of-hearing, from those born with their hearing loss to those whose hearing fades later in life. Nearly one in eight Americans has a bilateral hearing loss, and among people aged 70 and older the number rises to three in five. ${ }^{3,4}$ Some of those individuals sign; others might prefer to lipread. Some might strongly identify as culturally Deaf; others might view themselves as hearing people who have difficulty communicating in certain situations. Many people with hearing loss lipread to some extent, though when one's deafness is profound enough, using sign language is often a far clearer mode of communication. The diversity among people with hearing loss is staggering, making flexibility in the medical setting all the more crucial.

When I was young, I relied heavily on sign language support, and the medical system could sometimes seem ill-equipped to accommodate this need. When I was in first grade, my family left a reputable local pediatric dentist because her office would not allow parents to be present during medical procedures - even for a child with a disability. My mother explained my situation: I would be sitting in the dentist's chair unable to understand who was poking around in my mouth and what she was about to do to me. Couldn't the office make an exception and allow her to interpret? When they refused, we went elsewhere. I have heard about other deaf people who have also struggled with medical professionals' seeming unwillingness to provide full communication access. Refusing to write things down or to provide an interpreter is only the worst of it. Other behaviors, like failing to maintain eye contact or treating the patient as invisible while conversing with the interpreter instead, can feel nearly as demeaning. With or without interpreters, and medical procedure notwithstanding, visiting a doctor's office needs to be something that is done for me, not to me.

Sometimes, it is not even my conversation with the doctor herself that poses the biggest challenge in my medical visit. I arrive in the office and check in at the receptionist's desk, with someone who is usually sitting in front of a computer and who is usually paying more attention to the screen than she is to me. Her words can be fleeting and difficult to understand, but fortunately experience has taught me what will happen: I will say my name and the name of the doctor I am here to see and when, and she will thank me and tell me to have a seat, perhaps after asking me to update my insurance information. After checking in, I ask her to please wave and let me know when the nurse calls my name and then settle down in an empty chair.

While in the waiting room, I take care to position myself where I can see the nurse when she comes out and calls my name. I do the same in airports and other public places: even when I ask the people staffing the front desk to alert me when something important happens, more often than not they forget. Sometimes I pick up a magazine to pass the time, but always my eye lingers on the doorway. The process of calling patients back to the exam room is an auditory rather than a visual one, and more often than not I do not catch my name the first time the nurse says it, or erroneously respond when she has called someone else. 
When I reach the exam room, the nurse, even though I have told her I read lips, sometimes turns to her notepad or computer and asks me a rapid succession of questions Your height? Your weight? Have your medications changed? - without bothering to look at me. Then she catches me off-guard by asking for my arm to test my blood pressure, or asking me to sit up so she can listen to my heart. I have had this happen even in otolaryngology and audiology clinics, where hearing loss is prevalent. Often the situation improves when I stop the nurse and explain my situation, but already before I meet my doctor I feel embarrassed, worried about my ability to understand, and generally ill at ease. Even for hearing patients, for whom communication is not such a barrier, must it not feel disorienting to be treated in this brisk, laboratory-object manner? Slow down, I want to say. Look into my face and let me tell you what I need.

The doctors who do this - the ones who walk into the room and pay instant attention to my needs, who take care to maintain the connection, who ask how they can make communication easier - are the best ones. I have been fortunate enough to have many doctors like this. Even if I have never met a doctor who knew sign language, their good communication skills can help surpass the language barrier that tends to isolate people with hearing loss. And, even since I received a cochlear implant several years ago, which has made lipreading easier, I continue to believe that the doctors who exhibit such keen awareness of their patients' overarching needs tend to have excellent medical insights as well. After all, a good doctor ought not to be simply an ivory tower of knowledge, to whom patients must make a pilgrimage. He or she ought to be someone willing, humble, and flexible enough to ask those patients, quite clearly and directly, How can I help you?

\section{References}

1. Barnett S. A hearing problem. Am Fam Physician. 2002;66(5):911-915. 2. Ebert DA, Heckerling PS. Communication with deaf patients: knowledge, beliefs, and practices of physicians. JAMA. 1995;273(3):227-229.

3. Lin FR, Thorpe R, Gordon-Salant S, Ferrucci L. Hearing loss prevalence and risk factors among older adults in the United States. J Gerontol A Biol Sci Med Sci. 2011;66(5):582-590.

4. Lin FR, Niparko JK, Ferrucci L. Hearing loss prevalence in the United States. Arch Intern Med. 2011;171(20):1851-1853.

\footnotetext{
Acknowledgements

Some parts adapted from "Seeing at the Speed of Sound," Stanford magazine, March/April 2013, p.50-56.
}

Conflict of Interest Statement ct Funding

The authors have no funding, financial relationships or conflicts of interest to disclose.

Cite as:

Kolb R. How Can I Help You?: Perspectives from a Patient with a Hearing Loss. Int J Med Students 2013;1(2):94-6. 